\title{
Couchsurfing Along the Trans-Siberian Railway and Beyond Cosmopolitan Learning through Hospitality in Siberia
}

DENNIS ZUEV

\begin{abstract}
This article focuses on the process of cosmopolitan learning among hosts in a hospitality couchsurfing network in Siberia. The data making up the empirical basis for the study were collected during fieldwork in Siberia: between 2007 and 2011 in Krasnoiarsk and Novosibirsk and from 2010 to 2012 in Irkutsk and Vladivostok. The article argues that the interactional dynamics between hosts and guests in cosmopolitan learning are determined by the combination of emotive and cognitive rewards. The primary emotional charge occurs as a result of the first interaction with the visitor, while a cognitive "bonus" is represented by the opportunity to practice a foreign language in the home environment. In addition, hosts reflect on such aspects as the exchange of lifestyle ideas, the exposure to everyday habitual practices, and the realization of commonality and difference. These reflections leading to self-discovery in the comfort of one's own home constitute an important element in the process of cosmopolitan learning.
\end{abstract}

Keywords: cosmopolitan learning, couchsurfing, hospitality, mobility, railway, xenotopos

\footnotetext{
Couchsurfing is a computer-mediated hospitality network that allows members from different cultures and countries to stay in private homes for free. The main implication of this type of hospitality is direct, unmediated contact and cultural exchange between strangers. Usually couchsurfers stay one day, sometimes several days. The potentially risky event of two strangers meeting after only a brief online introduction and an email exchange is made safe via a system of references about the reputation of guests and hosts provided by other
} 
members. Even though there are "neutral-ground" community meetings (which vary depending on the size and activity of the local moderators), the host's home remains the major ground where relations between host and guest are established and communication occurs.

In this hospitality network, hosts and guests are driven by the opportunity of intercultural exchange, namely symbolic exchange (exchange of signs), which includes any form of communication, and exchange of information or data (Waters 2001). Sets of rules, norms, and ideas are exchanged symbolically. At the same time, exchange of material objects can also take place, and some form of mutual reciprocity is always implied and recommended by the couchsurfing code of practice. For example, a place to stay overnight provided by the host can be exchanged for interesting travel narratives, spatial knowledge (useful travel information about the area), or other symbolic goods, which can include the foreigners' verbal or visual narratives about their home country. One of the most important aspects of symbolic exchange that involves both parties is mutual reputation verification through the mechanism of references that both hosts and guest post about each other on the network. This process of writing of references is a crucial ritual in the exchange of signs of recognition and gratitude.

It is sociologically relevant to understand what the hosts and guests learn from each other during the exchange. In order to understand how couchsurfing contributes to the creation of global identities, the phenomenon is approached as a practice conducive to cosmopolitan learning, which requires a relational understanding of global connectivity (Rizvi 2008: 33).

Despite the fact that couchsurfing is a bounded community where some sociocultural differences are easily consumed and others easily rejected, it remains an important avenue for cosmopolitan learning. Recent upgrades of the "couch search" algorithm show the ongoing attempts of the couchsurfing administration to allow for a more balanced and egalitarian relationship between hosts and guests: all hosts are provided with equal status, regardless of their previous hosting experience. The process of cosmopolitan learning is particularly significant in the regional context of Siberia, where contacts with foreigners, especially from the West, have never occurred on a grand scale and where knowledge about new cultural formations and lifestyles are slow to be acquired.

For young people in peripheral cities, couchsurfing provides cultural capital. Active hosting allows users to have a feeling of connection to the world outside of their immediate geographic and lifestyle 
context, as well as to cherish commonalities with people in other parts of the world. Hosting as an act of giving also brings young people from a culture of low trust vis-à-vis strangers into a culture where trust can be mediated and established. By focusing on cosmopolitan learning, I demonstrate how hospitality is produced and interpreted by Siberian hosts in the era of the Internet and increased trans-border mobility.

Many of the Siberian couchsurfers that I interviewed have experienced foreign travel and even short-term living abroad. Some have relied on various practices of free-traveling (e.g., hitchhiking; see Zuev 2008a), whereas others have taken part in educational programs (e.g., the European Union's academic exchange program Erasmus Mundus) or large-scale commercial programs (e.g., Work and Travel, which is aimed at students who want to spend a summer in the United States).

Couchsurfing presents us with a vivid example of how Internetmediated networks change the ways young people meet and find a common language across national borders. Because couchsurfing is pursued mostly by young, Internet-connected people, it allows us to see how Siberian youth participate in the production of global mobilities, which imply shared values and the existence of a certain global community ideal (Kustov 2012).

The following research questions form the basis of this article: What constitutes learning in general in a couchsurfing exchange? How does "cosmopolitan learning" take place? Does the hospitality pattern change depending on the guest's origin? One would expect that people engaged in a hospitality network, and particularly young people in out-of-the-way places, would be enthusiastic about receiving any guest, yet they appear to have their preferences depending on what drives them initially to host. Although the idea of altruism and the wish to help are deeply rooted in the hospitality exchange, it is often the origin and the symbolic value of the guest that matter from the host's point of view. This symbolic value is closely connected with the particularities of cosmopolitan learning.

\section{Hospitality Networks and Cosmopolitan Learning as Topics of Research}

\section{Hospitality Networks: Between Online and Offline}

Hospitality networks such as couchsurfing have become the object of social scientific investigation only recently (see Germann Molz 2007). The studies of the topic have developed along two major lines: those fo- 
cusing on the online behavior and technological aspects of the Internetbased community; and those focusing on offline behavior, prioritizing broader moral implications of the practice and relational dynamics between hosts and guests. Many of the latter have revolved around the questions of trust and belonging (Delacruz and Claveria 2011; Rosen et al. 2011).

Discussions regarding the moral implications of technologically based hospitality networks provide valuable conceptualizations for this article on the values of couchsurfing as a mobility practice. Couchsurfing is conceptualized from three major angles-as a type of intimate tourism (Bialski 2007), as a social movement (Germann Molz 2012a), and as a practice of space appropriation (Pultar and Raubal 2009a, 2009b). One of the most attractive aspects of offline encounters is the actual process of reciprocal exchange (Germann Molz 2007), the expectations of the users (Chen 2011), and the power relations implied in the exchange (Bialski 2011; Chen 2011; Steylaerts and O'Dubhghaill 2011). The issue of power relations has been investigated by Bialski (2011), who has mapped the boundaries of couchsurfing hospitality. She argues that boundaries are set through reciprocity and the selection of guests by hosts. The reciprocity in this noncommercial exchange is vague and implicit, whereas the selection process, among other factors, may be determined by the host's own rules of safety. As Bialski concludes, disappointment among hosts is usually caused by breaches in pre-established expectations as to how the hosting space is utilized by the guests.

The interactional dynamics of host and guest have to a large extent been explored in relation to the context of Western societies. As a result, conceptualizations of hospitality networks have lacked regional foci, and the specificity of relationship between hospitality patterns and knowledge exchange in non-Western countries has remained unexplored, with the exception of a few case-studies on Africa (Buchberger 2011) and Asia (Chen 2011; Jesudhass 2011). Couchsurfing in Russia has been analyzed from a sociospatial perspective (Zuev 2011) and a globalization perspective (Kustov 2012). Couchsurfing is one of the forms of a newly emerging mobility culture in Russia and an integral element of tourist infrastructure in Siberia. However, mobility studies on Russia, and particularly those on Siberia, are characterized by rather belated attention to changing spatial patterns, mobile technology use, and mobility practices (see Popov 2012).

Studies of the couchsurfing community in Russia contribute to quite a large body of research dedicated to various youth subcultures in con- 
temporary Russia (Pilkington et al. 2003; Pilkington et al. 2010). However, negotiation of place and particular spatial practices of youth movements have rarely been studied in detail (e.g., Walker 2010). While deviant youth subcultures (such as skinheads, neo-pagans, or gopniki) in Russia have received a fair share of attention (e.g., Aitamurto 2007; Gavriliuk 2010; Golovin and Lur'e 2008; Pilkington et al. 2010 ), the groups and communities that propagate cosmopolitan learning and encourage openness to diversity receive less attention from social scientists. At the same time, it is argued that research on consumer practices, lifestyles, and forms of representation of individual and collective identities should not be left on the margins of Siberian studies (Habeck 2008). Couchsurfing provides us with an opportunity not only to observe the process of consumption but also to investigate how mobilities are being produced and facilitated through acts of hospitality in Siberia.

\section{Couchsurfing and Cosmopolitan Learning}

Couchsurfing provides an empirical example by which to examine cosmopolitan learning as it occurs among young people in the context of the global circulation of people and objects. In a broad sense it is "a mode of learning about, and ethically engaging with new cultural formations" (Rizvi 2008: 21). I use the term in a more definite sense-the development of cosmopolitan orientations and openness toward a variety of cultural codes that come into play during intercultural interactions between host(s) and guest(s).

Jennie Germann Molz (2007: 78) states that couchsurfing as well as similar hospitality exchange websites are infused with cosmopolitan fantasies of "bringing the world home and feeling at home in the world." Hosting others, she suggests, is a move to change the world through learning about different cultures in the comfort of one's own home: when you are at home you do not travel physically, but you still "travel" by receiving guests from other cultures. This observation is supported by my own findings, and several interviewees in this article discussed it. Considering that travel to other cultures is still not a widespread phenomenon for the majority of young people in Siberia, being able to experience mobility flows and establish contact with other cultures while feeling "anchored" or even "stuck" at home can be one of the most attractive aspects of couchsurfing.

As I have argued elsewhere (Zuev 2011), couchsurfing is a practice that generates a specific type of space-xenotopos, a space of the "other" 
(Barth et al. 2010) or space of strangers interacting (Zuev 2011). One of the properties of xenotopos is that for the host the guest is a stranger who helps to see the home space in an unfamiliar way and to reveal the human commonality between host and guest notwithstanding their different cultural backgrounds. At the same time, the host is an "authentic" representative of a foreign culture and lifestyle for the guest who is situated in an unfamiliar terrain. Frequent xenotopic exchanges make up the fabric of couchsurfing and enforce a cosmopolitan vision of space. The familiar for the host becomes unfamiliar; likewise, the unfamiliar (exotic) for the guest becomes more familiar and intimate. The host, through individual self-presentation, represents social space as a "humanized place"; simultaneously, the openness of the host comes to symbolize the openness of the place. In this sense the interaction of guest and host makes the place a cosmopolitan one. The relational dynamics of host, guest, and the place of hosting are crucial components in understanding how couchsurfing works and how hospitality is produced in Siberia (Zuev 2013).

Expectations of the host along time and space dimensions lead us to think about how hospitality is provided and about the conditions under which hosts agree to provide and be engaged in cross-cultural exchange. I suggest that cosmopolitan learning has two integral aspects: emotive and cognitive. In fact, learning here means informal learning through encounters with guests, to whom hosts willingly open the door and dedicates their time. The "warm glow" (Andreoni 1990) of helping those who do not know the local situation is an emotional reward. In addition, experiencing such emotion comes from realization of commonality with people from other cultures despite language differences. The cognitive aspect of learning is comprised of exchange of views and ideas and-on a more mundane level-the daily practice speaking a foreign language. The goal of this article is not only to provide an analysis of empirical data with regional focus on Siberia but also to contribute to our knowledge of hospitality practiced in this part of the world and simultaneously to advance the conceptualization of new forms of mobility in Russia.

\section{The Profile of Couchsurfing in Russia}

Comprising only 3 percent of the global couchsurfing community, ${ }^{1}$ Russian membership is quite modest but has nonetheless shown rapid growth. There are currently 63,000 individuals claiming to be mem- 
bers, which is twelve times more than in 2008. However, these figures merely indicate the number of couchsurfing profiles. The number of active hosts is much smaller, and the number of surfers traveling is even smaller. Profiles tend to be established but many are never fully completed or are abandoned, or both. The number of profiles can be used by the website's administrators to advertise their success in attracting new followers, but the number as such does not correspond with the actual places where couchsurfers can stay when traveling. One parameter that helps to attain a more realistic estimate is the number of profiles with photos. In Russia it is at about 60 percent, which brings into question the activity and self-presentation concern of the other 40 percent of users. In computer-mediated communication in general and in social networking sites in particular, the individual's visual narrative is the most important part of self-presentation (Hancock and Toma 2009; Zuev 2008b). A lack of photos implies either that some users do not have a sustained interest or that they underestimate the importance of one's visual self-presentation. Yet another explanation could be that the idea of global hospitality is more enticing than the actual investment in social relations that comes with it.

The couchsurfing network allows a high degree of flexibility in terms of organizing an offline encounter and choosing the form of hospitality. According to official statistics on availability of couches for surfing, 44 percent of Russian surfers prefer to list their status as "coffee or drink," which in my experience usually means that they are not really willing to host at home but rather prefer to meet offline on neutral ground. Only 25 percent are willing to host, while 16 percent are not available for hosting (stating in their profile that they have "no" availability or are "traveling at the moment"). Another 15 percent indicate that "maybe" they can host somebody, which makes potential surfers prefer other options and profiles.

Couchsurfing is a practice predominantly used by young peopleover 80 percent are between the ages of 18 and 29. A particular, interesting feature of the Russian couchsurfing community is the high percentage of female members (around 60 percent vs. 34 percent male population, with 6 percent being couples). The couchsurfing communities in the two largest cities-Moscow and St. Petersburg-make up around 60 percent of the Russian couchsurfing population and outnumber those in the rest of Russia by far. The dominant position of Moscow and St. Petersburg can be explained by many factors: the level of the Internet development in these cities is higher than elsewhere (Cooper 2006) student population is particularly large; and the cities 
are two major hubs of the transportation network and have the embassies and consulates where residents of Siberia apply for visas. ${ }^{2}$ Being the main attractors of internal migrants, tourists, and expatriots, Moscow and St. Petersburg have large segments of nonlocal residents who bring their own practices and understanding of hospitality to these big cities. As for Siberia, three cities-Novosibirsk (1265 users), Irkutsk (968), and Krasnoiarsk (816) - feature among the top ten couchsurfing cities in Russia. ${ }^{3}$ Together, the three cities have a membership of approximately 3,000 . The author has conducted participant observation and interviews in each of these three cities from 2008 to 2011, and these data provide the empirical basis of this study.

\section{Couchsurfing along the Trans-Siberian Railway}

As the last section has shown, couchsurfing in Russia comprises only a small segment of the global dynamics of couchsurfing, and within this small segment, the number of couchsurfers in Siberia is small. There are certain reasons for this: Siberia as a couchsurfing destination is not even closely comparable to popular mass tourism or backpacking destinations where foreign tourists arrive by the hundreds, being able to rely on a well-developed tourist industry. Getting to Russia requires a visa, and the experience of applying for it serves as a reminder (primarily to "first-world" travelers) that travelers are entering a region where their mobility is limited or controlled. Aside from such bureaucratic requirements, couchsurfing in Siberia is very much affected by seasonal rhythms and transportation flows. Most travelers visit Siberia in the summer, shying away from the low temperatures during the rest of the year; most stay with the most practicable itinerary, the Trans-Siberian railway, having no time or incentive to "divert" from it to the Far North.

In Siberia, couchsurfing is determined by the dialectics of several contact-constraining and contact-facilitating factors. One of the factors that facilitates contact is the relative isolation from mainstream tourist flows and the small number of visitors who speak Russian, so that a couchsurfer is seen as a valuable asset, a potential partner who enables one to practice one's foreign language skills. The contact-facilitating factor is related to the notion that a traveler in Siberia is a rather infrequent and exotic figure, who is therefore considered to be worth establishing contact with and taking care of. The foreigner may be treated as someone who, by the very fact of having arrived in Siberia, has shown 
his or her potential for overcoming difficulties in a country where life is considered unpredictable and frustrating, even by local inhabitants.

Besides the language barrier there are other contact-constraining factors. Some of these have been briefly mentioned before: a visa for the Russian Federation is rather difficult and expensive to get, and in many places the tourist infrastructure is undeveloped and lacks some of the most conventional backpacking institutions such as youth hostels and Internet cafes. Couchsurfing effectively solves several problems related to traveling in Siberia: the language barrier, access to spatial knowledge, and access to accommodation.

In some of the Siberian cities, couchsurfing has become an important, albeit invisible, element of tourist infrastructure. The free maintenance of this infrastructure is conducted by the members-young people, often relatively fluent in foreign languages, who can share useful travel information about the area (i.e., spatial knowledge). Through couchsurfing travelers from the West can get access to the backstage of Siberian daily life and, as a rule, stay in a comfortable and safe place for free.

Even if the city is not a very touristic one but offers good connections for traveling - as is the case with Novosibirsk - it still may have a sizable community of members. Novosibirsk is well connected to the east and west of Russia, being the base of S7 Airlines and at the same time serving as a railway junction to Central Asia. Even if it is not regarded as the most popular stop for Western couchsurfers on their Trans-Siberian journey, it is an important exit point for those who plan to travel to the Altai Mountains.

Surprisingly, the size of the city in Siberia is not always related to its mobility-facilitating infrastructure. Irkutsk is a much smaller town than Krasnoiarsk but is better connected to Asia. It has several diplomatic missions that ease the procedure of getting visas for the onward journey, while Krasnoiarsk, despite its larger population, has not one diplomatic mission.

Unlike Krasnoiarsk, Irkutsk has always been an open city, and already during Soviet times it featured an Inturist office and received a large number of foreign students. The tourist business related to Lake Baikal is now booming. Irkutsk is the hub of connections to Lake Baikal and perhaps for this reason offers the highest concentration of youth hostels in Siberia. Surprisingly, during my fieldwork in 2011, Irkutsk did not seem to be a well-connected city. One aspect of mobility-facilitating infrastructure is the availability of Wi-Fi points and, according to my observations in 2010-2011, it was difficult to find a reliable and free 
Wi-Fi connection in Irkutsk, while in Krasnoiarsk it was widely available in many cafés, cinemas, and hotels. ${ }^{4}$

Rarely do couchsurfers travel all the way from Moscow to Vladivostok. A typical Couchsurfer makes a Trans-Siberian journey from Moscow to Beijing with en route stops in Krasnoiarsk, Irkutsk, and Ulaanbaatar (Mongolia). Online forums and a couchsurfing group called the "Trans-Siberian Train" provide a special platform for those surfers who are traveling by train or along the railway. ${ }^{5}$

The rhythm of couchsurfers' movements in Siberia is to a great extent conditioned by that of the seasons. If the couchsurfing communities of Moscow and St. Petersburg enjoy a rather steady inflow of surfers all year round, in Siberia summer is the most popular time. Even in Siberia there are slight seasonal variations in couchsurfing flows. It is difficult to give accurate estimates, but according to the observations that I made while being a registered member in Krasnoiarsk and Irkutsk from 2009 to 2011, I can state that in Irkutsk there were couch requests already submitted in February, while in Krasnoiarsk the bulk of requests occurred from the end of May to the end of September. The couchsurfing season in Krasnoiarsk is shorter, whereas Irkutsk hosts people for a much more extended period of time. Some surfers come to Irkutsk in the winter to experience ice-covered Lake Baikal or for alpine skiing in Baikal'sk.

Bureaucratic requirements play a crucial role in couchsurfing decisions. Foreign couchsurfers arriving on a tourist visa are allowed to spend one month in Russia; this sets a limit on the traveling rhythm. When asking some of the visiting couchsurfers about their trajectories, I learned that one week (or more) of the one-month visa duration is spent in St. Petersburg and Moscow, whereas the rest of the time is allocated to the Trans-Siberian Railway trip with a short time off somewhere along the route. Moreover, the rhythm of movement is to some extent defined by the immigration policy concerning foreigners: one can stay in a location for three working days without registration (weekend days are not counted). It means that couchsurfers spend a maximum of two nights in a place and then catch another train.

Couchsurfers traveling along Trans-Siberian often rely on travel agencies for getting visas and tickets, and these agencies sell tickets for a berth in a four-bed compartment (kupe). However, in order to experience "a different feel" and a more authentic experience, many members of the Trans-Siberian Train forum advocate traveling in a lower-category sleeping car, where all passengers share the same space (platskart). This different feel and closer contact with local people may 
also be a motivation for couchsurfing because it provides a different emotional and cognitive dimension of the trip-a more intensive one than that of a trip organized by a travel agency.

Reliable statistical data on the growth of couchsurfing community in Russia are scarce. According to the official statistics provided by the website, which I have collected between 2009 and 2011, communities in Russia and in Siberia have experienced very uneven growth rates. For instance, the community on Sakhalin Island grew from 0 in 2009 to 76 members in 2011, and in Vorkuta from 1 to 3 members. In general, communities in popular couchsurfing cities along the Trans-Siberian Railway have expanded quite rapidly from 2009 to 2011.

The rapid growth of couchsurfing membership in Siberia allows conjecture that it is becoming an important, even if rather invisible element of the tourist and mobility infrastructure in Siberia. It facilitates the travel of predominantly young people and allows intercultural exchange to happen on a wider scale than before, when the couchsurfing community did not yet exist in Siberia. The number of couchsurfers also provides a useful indicator for measuring the tourist potential of cities along the Trans-Siberian Railway.

\section{Methodology of the Study}

This article is based on my ethnographic study of couchsurfing as it is practiced in Russia through collection of data by interviews and participant observation. Since 2011, interviews in Krasnoiarsk have been supplemented by semistructured interviews conducted within the research project "Conditions and Limitations of Lifestyle Plurality in Siberia." Sixteen interviews were conducted in Irkutsk in the spring of 2011 and in the spring of 2012, and an additional 10 were conducted in Vladivostok in the summer of 2011.

These data complement an earlier study done in Krasnoiarsk, which was based on participant observation during a four-year period from 2006 to 2010, including online analysis and 15 in-depth interviews. The interviewees were selected on the basis of having both hosting and surfing experience, as well as on the basis of their living arrangements (rented apartment, shared room, separate room, parents' apartment). Of the interviewees, 75 percent were female, the majority being between the ages of 20 to 30, with the youngest interviewee being 19 and the oldest 52 (see Table 1). As noted earlier (Zuev 2011: 234), domination of female couchsurfers both in terms of active participation 


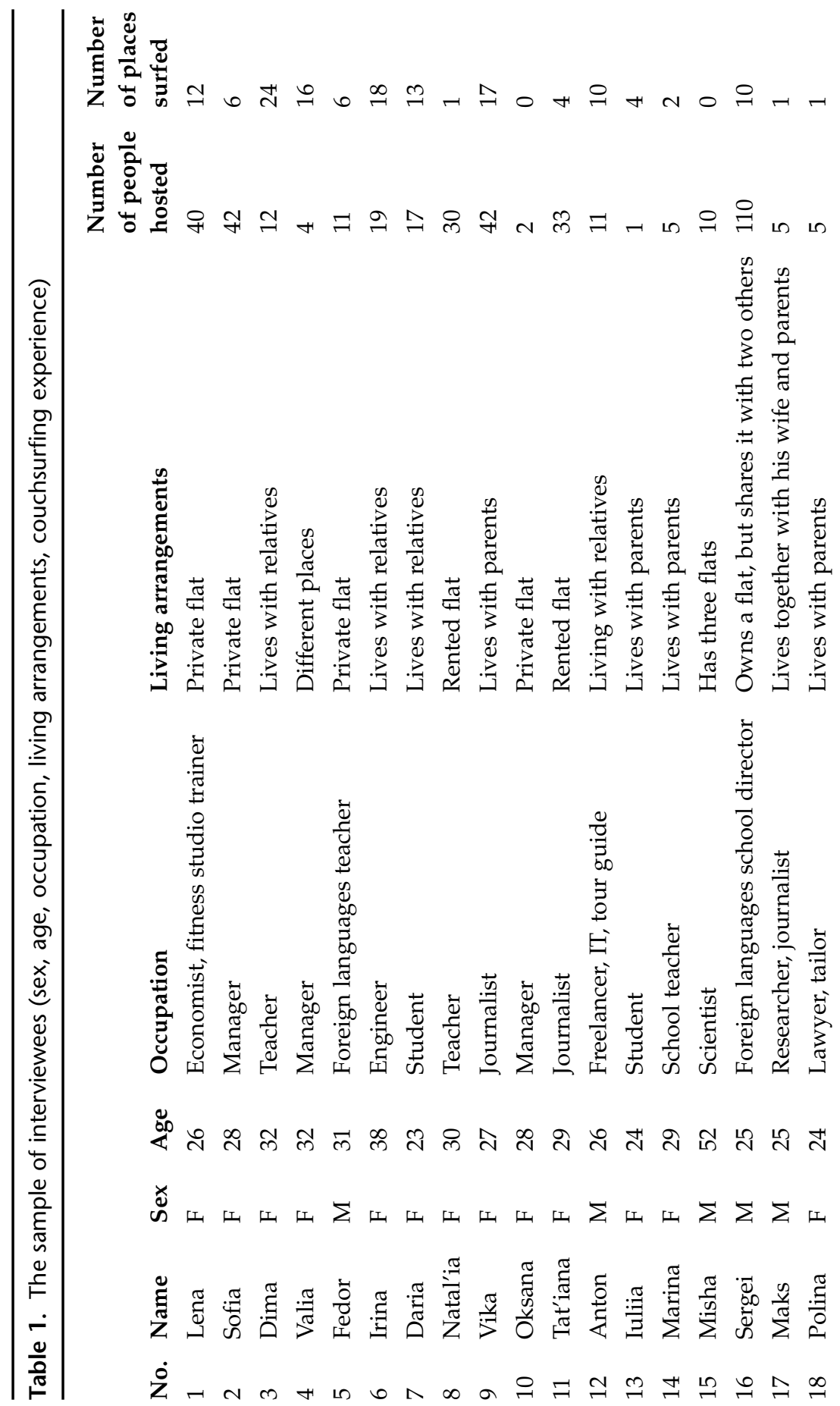


and numbers in Russia can be regarded as one of the peculiar general characteristics.

Potential interviewees were contacted via the couchsurfing website with a direct request to meet for an interview. Later, the interviews were conducted on neutral ground (in the city's public spaces such as cafés) or in my apartment. In several cases I was invited to the interviewee's home. A significant part of this study is comprised of the informal "mobile" conversations that I had while traveling by bus, car, ferryboat, bicycle, or on horseback. Thus, the interview process was advanced by traveling together with some of the couchsurfers.

Methodological implications of studying couchsurfing through virtual mobile ethnography have been comprehensively outlined by Jennie Germann Molz (2012b). Using this approach in my research, I followed some of the travelers' narratives and partly "co-moved" with them physically in geographic space. In some cases, following travelers' connections also meant meeting their parents, spouses, friends, using their bicycles, meeting their couchsurfers, and seeing the spots and itineraries by which they make foreign surfers acquainted with their home territory. It is no surprise then that some of them stayed at the apartment I rented, shared food, photographs, traveling impressions, and became friends. These informal conversations, joint travel experience, and experience of living together with hosts and guests have contributed greatly to understanding the meaning of mobility and immobility for the young people in Siberia.

Researching hospitality in one's own country as it is practiced toward foreigners is not without challenges. Being from another city in Siberia and presenting myself as working in another country (Portugal) may have had an impact on the information that was disclosed.

\section{Emotional Rewards of Cosmopolitan Learning: Feeling Strangeness and Sameness with the Other}

The idea of emotional intensity in brief encounters and the intimacy created between the host and guest in couchsurfing has been earlier developed by Bialski $(2007,2011)$. In particular, Bialski outlined three stages of the host-guest familiarization process: introduction, insight, and embedding. She emphasized that conversations have the highest emotional intensity within the insight stage; the closeness is felt at its strongest and this is the moment of proximity when the host and guest learn about each other. However, life narratives are exchanged 
throughout the process, emotional insights are spontaneous, and the most habitual actions or behavior are crucial and take time.

In the interviews conducted in Krasnoiarsk, I noticed that most couchsurfers tend to emphasize how emotionally exciting it is to establish primary contact with a stranger on their own and maintain itstarting with the first online message and finishing with the farewell at a railway station. Participation in couchsurfing provides, for many members of the local community, the chance to immerse in a flow of unfamiliar things-language, customs, objects, ideas and stories-in the comfort of their own home. Often the hosts I interviewed in Krasnoiarsk reflected on the opportunity to experience the world outside their home, even though being "stuck in a provincial swamp" for various reasons (lack of money, lack of time to travel, having young children, lack of knowledge of how to travel less expensively). "Immobile" hosts who themselves have not surfed did not talk in terms of cosmopolitan values - in terms of "being at home in the world"; instead, their discourse was marked by such terms as "finding a common language" or by their experience of encountering positive examples of a different way of life. The feeling of discovering commonality across geographic and cultural boundaries is an oft-reported experience of the couchsurfers in Krasnoiarsk, and the discovery of such commonality are rewards of the time and energy that the host spends on communicating with the guest, as can be exemplified by this statement:

Still, there are more pluses than minuses. Communication. You see that people can live a life completely different from yours. I could not understand how one cannot work from nine to five, how one can live like this. You can live beautifully. I always ask about how they manage ... And from them I get these moments that help me organize my life. (Natal'ia)

Here the respondent discussed how her life experience of being a young single mother has become more diverse through couchsurfing, which she stressed she used "90 percent for English-language practice." For many (young) Russians, to pursue a mobile lifestyle, to spend considerable time outside of home, to visit various places and not just a seaside resort, and to find one's own way around and not just rely on a package tour are still novel options, ones that are not easy to fulfill. In this case the host's encounter with the unusual lifestyle of constant mobility, supposedly originating in the West, clashes with familiar versions of a "normal," sedentary lifestyle, dictated by the conventional labor habits of a 9 to 5 job. 
Couchsurfing provides a space for connections where recipes of life management and movement are exchanged. A Russian single mother meeting an Argentinean couchsurfer who sold her car to travel the world becomes a moment of revelation that there are multiple ways to organize one's life and to overcome imagined and real spatial constraints. Guests who use unconventional means of transport (motorcycle, bike, or wheelchair), or have unconventional eating habits (vegan) add to the perception of "strangeness" and become the triggers of imaginative work through which the host tries to understand relationships and envision alternatives to the existing order of things. As one of the couchsurfers in Irkutsk declared, the strangest experience for him was hosting a disabled Polish surfer, who moved around on a skateboard with a huge backpack. This contact helped him to normalize his vision of disability and to "put tolerance on another level. It makes you reflect in general, review your personal discontent about life" (Sergei).

Oksana, who lives in a small one-room apartment, has not hosted many surfers and has never surfed other people's couches but reports that she hosts when she is in the mood. For her, too, the primary reason to host somebody is "to communicate, practice English." But what she finds particularly significant in hosting is the "energy exchange" (obmen energetikoi), when "you are ready to spend 24 hours with one person." The energy seems to be flowing when the other person reveals common features to share with you, including peculiar traits of behavior or habits. Oksana fondly remembered:

This French girl. She was such a person! First of all, she was so much like me. Her philosophy, her attitude to life, we found such a common language with her that I did not want her to leave, wanted to talk to her more, go with her somewhere. None of my friends understands why I dip a cookie or a [piece of] chocolate into my tea or coffee. We were drinking tea and she said: do not pay attention, I like to dip my chocolate into my tea. I almost fell off my chair. It was amazing, a person lives so far away, and we are still so much alike.

Oksana's discovery that a strange behavioral detail of hers - which even her Russian friends did not understand - shared by a French guest is a vivid example of the host making a discovery about herself. Through the guest from another culture, she sees herself as if in a mirror. Cosmopolitan learning in couchsurfing is so striking because simple realization of habitual sameness across cultural borders comes in everyday interaction rituals, such as a shared meal. This de-exoticization of the 
foreigner, realization of shared behavioral patterns between the host and guest, can be one important asset in the production of positive emotions during the act of hospitality. Saito (2011: 125) states that divergent cultural experiences involve encounters with foreign people's practices. In cosmopolitan learning, exposure to strangers presupposes exposure to "strange" practices that may be invisible at first sight. As one host in Irkutsk noticed, surfers in his home were often startled by the amount of milk he added into his omelet and he added a detailed reflection on what he thought "makes a person different," an "other."

For instance, our water and electricity are cheap ... And I have a habit from my childhood that the water is flowing when I brush my teeth. I brush my teeth and the water flows. And we were talking about something, I am walking around brushing my teeth ... the door is open, so there is no secrecy or privacy ... we are talking and laughing. A surfer comes inside the bathroom and turns my water off. Just goes inside and turns off my water. What is that? The water is flowing, so what? Then I understand, sure, in Europe, water is expensive, and I am not appreciating it here. (Sergei)

This reflection of Sergei serves to display how a host can be reminded of another cultural system of coordinates that exists outside of his home space. The gesture of a guest can have a two-way interpretation - as care about the host (not to waste money) or as involuntary interference in the comfortable everyday order. The guest thus creates an emotional reaction, and this triggers a need to manage comprehension between the host and the guest. Another host in Krasnoiarsk recalling a similar context of household management added that she learned to automatically turn off the light after her guests who "never turned the light off after themselves." She made this minor correction with no negative emotion as she remarked with a smile, implying that she had had to develop a strong awareness of cultural nuances when having guests with different cultural readings of domestic rules.

As in many relatively isolated nontouristic locations, having a guest for the first time is an adventure, an adventure at home. What can be more exciting than establishing contact with an unknown person for the first time? And with further hosting comes the realization that cultural boundaries are not fixed; that there is universal basis for human interaction, and that some sort of internationalism or cosmopolitanism is being produced:

When we stayed and were guests for the first time, we could see that it was simply interesting to establish the first contact ... when you 
gather experience and see that people are the same. We are born in different points of the Earth, and so we have some minor differences in skin color, we culturally develop in different places, so your perception of the world is such ... [but] on the whole, we are, as peoplethe same, absolutely. (Anton)

Anton's remark reminds us of the "sameness" dimension, which is considered one of the important aspects in negotiating the borders between us and them (see Baerenholdt 2011 and Gullestad 2001 on "imagined sameness"). The sameness that is perceived by surfers in the act of hosting suggests that experiencing another person's home enables one to fully appreciate such sameness despite all sorts of cultural differences.

Generally, hosting in Siberia seems to be characterized by the idea of breaking through the geographic isolation of the region in order to experience difference and commonality across physical borders. For some of the respondents, Krasnoiarsk is still in the middle of nowhere, not just at the periphery, but, as one couchsurfer sadly perceived it, "the ass of the world," a place without sun, far away from where she would like to be.

Tat'iana, a host living in Irkutsk, describes it as "a small town, a lot of acquaintances, you can find acquaintances through acquaintances, so it is difficult to get lost in such a town. You know all the streets here-you know everything." Tat'iana feels that there is nothing to discover in such a small town, and only through proximity to another culture in the act of hosting is she able to be inspired to be more active. The foreign guest "infects" her with positive emotions when sharing stories. Tat'iana shared her emotions after the encounters with her guests: "I have not surfed myself, but the people who come, contaminate with this spirit. They start telling about different countries, about different places where they stayed. And really you want to go away literally the following day. Set yourself free and go far away."

The exchange of travel stories can be conducive to cosmopolitan learning, as for a moment it creates emotions that let the host forget about everyday life, work, borders, and visa requirements. This upsurge of feeling closeness with undiscovered places is an important condition in a transformation from feeling locally connected to feeling globally connected. As Rizvi notes, learning about global interconnectivity has the potential to help people "come to terms with their situatedness in the world-situatedness of their knowledge and of their cultural practices" (2008: 30). 
Interestingly, many hosts in Siberia associate the experience of hosting and encountering a foreign traveler with a perception of making a spatial contact with not simply strangers but "people from another planet" (Anton). The "contact with extraterrestrials" may be a powerful metaphor indicating that the perceived distance between the host's and surfer's cultures can be tremendous.

It is a chance to communicate with people, let's put it this way-from a different universe, sort of an alternative one. Every time when they come there is such a feeling, that you are talking to extraterrestrials (inoplanetiane). Different mentality, different language, speech peculiarities, people, different behavior of people who are so much different from you, from Russian people, but nevertheless there are common points. There are such points. (Tat'iana)

This host's remarks show that couchsurfing provides a platform from which to confront cultural differences offline, and to search for common points, whereas the challenge of intercultural communication may become one of the motivations to continue couchsurfing. Establishing first contact is one of the most exciting aspects of hosting, while showing the beauty of one's home is also emotionally rewarding. In fact, as Bialski (2011: 257) observes, hospitality is caused by the wish of the host to prove to the guests that the place where they are living has its own value, both aesthetically and morally. One of my personal intentions as a host has been to show the places around Krasnoiarsk that are not listed in popular guidebooks, and not to share travel stories but to share the awe of contemplating gorgeous landscapes, which may be so close to the polluted industrial city that they are not on the conventional path of tourists. Learning about others is accompanied by a feeling of pride to show the best that one has, sometimes in more conventional ways than in my own case: "There is a route for guests, it is very simple; I think all hosts follow this route. It is meant to show the city from its best angles. Here I want to be a patriot. I don't scold ... I don't show the rubbish dumps. I show the things that are beautiful" (Misha).

Diverse elements may contribute to amplifying the emotional component in cosmopolitan learning, from establishing first contact with strangers and proudly letting them enjoy the local highlights, to discovering differences in habitual actions across cultures and exposing oneself to "strange" practices such as eating vegan food. However, the emotions involved in learning are supplemented by two important pragmatic-and as I argue, cognitive-objectives. 


\section{Cognitive Rewards of Cosmopolitan Learning: Language Lessons and Awareness of Cultural Diversity}

In addition to the moments of emotional intensity provided by the first encounter and the revelation of similarities and differences, some couchsurfers in Siberia are driven by pragmatic reasons: if there are foreign guests, one should practice their languages. As some of interviewees pointed out, foreign guests were assigned higher exchange value. The guest's being from abroad already contained an element of the unknown. Younger hosts were demonstrating more enthusiasm about hosting foreign guests, hoping to experience and feel a real cultural difference. As one host, Daria, told me, "I am more interested in foreigners than in Russian travelers. It is obvious. Foreigners are often more interesting than Russians, who just travel along the Trans-Siberian [Railway] and think that they know Russia very well." This tendency to be more open toward and fascinated by foreigners is rather common in Siberia, since the presence of foreign-language speakers is relatively rare. Without any doubt, in such locations as Krasnoiarsk, couchsurfing is beneficial for both hosts and guests from abroad. Guests are able to access English-speaking locals, which makes their stay easier, less stressful, and more meaningful. Hosts are able to practice English with native speakers or with people fluent in English. Practicing English is an important aspect of preparing oneself for couchsurfing abroad:

It is very important. Because going to the English or Spanish courses is of absolutely no use. When you start communicating in everyday situations with a native language speaker, it is a completely different matter. ... I have no language preferences, but language is definitely one of the main bonuses you get from the process. (Marina)

One of the interviewees, an English teacher, hosts native English speakers and invites them to her class to talk to her students. The way the couchsurfer interacts with her students and responds to her request becomes an indicator for her whether the host-guest relationship has been successfully established. Thus, she benefits not only individually from the cultural resources introduced by the foreign traveler but also uses the native speaker to structure her lesson and distribute the language resource among schoolchildren who rarely have direct contact with people from another country. 
The crucial importance of direct communication as a reward for hosting is also documented by the fact that some hosts report they are less happy with having more than one guest (for example, a couple). There is generally less opportunity to connect with those surfers as they are likely to communicate mainly with each other. One of my interviewees, Natal'ia, has shared this experience: "If there is a couple coming, it means they will be with each other; you will be sort of 'third one out' (tretii lishnii). You will communicate with them less than if one to one." It appears that Natal'ia's main motivation for participation in couchsurfing is the chance to communicate in a foreign language rather than simply altruistically providing a place to stay.

To be fair, the attitude that some guests can be more welcome than others is not shared by the majority of the couchsurfers that were interviewed for this article. In particular, those interviewees that have hitchhiking experience in Russia claimed that there were no differences between whom to host; for them, all people were worthy of hospitality.

In terms of cognitive insight, hosts in Siberia may also be looking for an opportunity to see themselves through the eyes of those who are culturally different (as well as to practice this alternative view within their own experiential space through an imaginative switching of positions). This is why surfers who are unlikely to provide this alternative are deemed to be less worthy, and since Russian surfers are considered to be like "us" (hosts) they supposedly cannot tell much new about the world outside Russia, unless they have travelled or lived abroad. Despite the cosmopolitan ideological statement of the couchsurfing community, it seems more difficult to create trust toward "close" (domestic) strangers than toward distant strangers. Some members of the community claim that travel history adds to the reputation of a guest: a guest is expected to be interesting because of his personal travel history. If one travels a lot, one has many stories to tell and will find it easier to communicate. Russian travelers apparently are regarded as not so well traveled; hence, they are met with less enthusiasm and with more distrust:

Maybe a person has been to many places already. It is not so much trust, but rather interest. As for trust towards people, especially Europeans, I have no problem. Nothing bad can happen ...

D. Z.: And what if the couchsurfer is Russian, Turkish, Chinese, nonEuropean? 
With Russians it is more complicated ... With Russians I would ... It is more difficult to trust Russians. Although, if speaking about myself, if I would go somewhere, the thought of taking something from someone's place would never occur to me. (Oksana)

Oksana's selective hospitality discourse shows that couchsurfers are geared toward intercultural exchange and contacts but not toward contacts with random strangers, even if they are members of the same network.

Having identified the emotional and cognitive rewards of the hosting experience, I close this section by providing an example of how these aspects may overlap. Anton is a typical example of a hypermobile Siberian youngster. He is an ex-computer scientist turned tabla player, who now independently organizes and personally guides trekking tours in India and Nepal from Krasnoiarsk. He spends the Siberian winter traveling on his own or guiding tours in India and comes back home in late spring to participate in summer music festivals in Tuva and Khakassia. He started hosting within the Hospitality Club network and later embraced couchsurfing, actively participating in the local community meetings and mediating the local community discussion group. Anton is constantly immersed in the rhythm of mobile intercultural communication: he spends several months traveling and when at home he hosts surfers in his room in his parents' threebedroom khrushchevka apartment. ${ }^{6}$

By traveling you see the world in a wider perspective, and when you do not travel you still reach the same goal ... using the website, when you travel you can touch the world as the locals do. When not traveling, in the breaks between your trips, as it is usual in most of the cases, you can still help people like you. (Anton)

Anton's comment suggests that couchsurfing indeed means to let oneself be attracted by the rhythms of continual movement of cultures. The moving couchsurfers are carriers of these cultures and values, behaviors, and attitudes. Even when "stuck," a host is still an active agent in facilitating the mobility of other travelers. Hosting in the midst of one's working time can be as pleasant as going on vacation, or at least offer the possibility of an "offbeat" moment to slow down the hectic rhythm of the daily routine. The host's habitual everyday rhythm is thus syncopated by the couchsurfers' visits, and the host finds time to become immersed in memories or stories of distant familiar or unfamiliar places. In particular for people who perceive themselves as 
(temporarily) immobile, hosting is a viable way of substituting one's own immobility with a different regime of encounters.

\section{Conclusion}

The appearance of couchsurfing as a mobility-facilitating practice has contributed greatly to young people's ability to expand their personal geographic and linguistic maps. It allows young Siberians to travel abroad but also to receive people from other cultures at home and to share their vision of their homeland with the visiting foreigners. For most couchsurfers, it is a way to learn about others - the primary cognitive reward in cosmopolitan learning. Moreover, the awareness of closeness or sameness across cultural borders comes in everyday encounters when the living space of an apartment is shared by hosts and guests, and similar behavioral traits are discovered in manifold ways.

One of the findings of this study is that some of the Russian hosts actually consider couchsurfing as a practice designed for cultural exchange with foreigners and distant strangers rather than for hosting and communicating with Russian travelers. This is the paradox of the hospitality network in Siberia - it helps to raise awareness about other cultures and learning of other languages, but its cosmopolitan learning agenda excludes those people who share the same language. Is the process of cosmopolitan learning opposed to, or even detrimental to the idea of local embeddedness and local solidarity? Does couchsurfing have a degrading effect on national consciousness? These questions are to be addressed in further studies, but as some of the findings show, being a host involves showing one's home and hometown from its best side and that the pride that derives from the guest's appreciation of the beauty is one of the emotional rewards. This finding is also supported by the theoretical argument of sociologists that localism and cosmopolitanism are not to be treated as mutually exclusive phenomena (Gustafson 2009).

For those young people who are actively involved in couchsurfing, the contact with others-mediated via the Internet-creates an important basis for potential mobility inside and outside of Siberia, a preparatory step toward practiced mobility. If surfers consider that they have no chance to see the world, the world may come to see them. As a platform where cross-cultural differences can be juxtaposed and reflected upon, couchsurfing allows young people to feel the connection with a greater world beyond their local one. The study of hospitality network- 
ing allows us to pose new questions about the moral implications of hospitality in peripheral regions off the well-trodden tourist tracks and to examine perceptions of "strangers" in contemporary Siberia.

Dennis Zuev, PhD, is a research fellow at the Centre for Research and Studies in Sociology, CIES-ISCTE, IUL in Lisbon, Portugal. He serves as vice president (research) of the Visual Sociology Working Group 03 working under the International Sociological Association. He has published articles on symbolic politics and nationalism in Russia, mobility, and the visual analysis of YouTube. He is co-editor (with Regev Nathansohn) of the volume Sociology of Visual Sphere (Routledge, 2012).

\section{Notes}

1. In the previous search procedure, the top hosts were listed in the beginning with the less popular hosts following them. Since 2011, this distinction has been eliminated.

2. The largest segment of couchsurfers are residents of the United States (30 percent).

3. These data originate from the official site statistics, which have been saved by the author over the past five years in order to follow the dynamics of community change. Data for the current year were available at http://www .couchsurfing.org/statistics.html but are no longer in public domain.

4. In some cities in Europe (like Akureyri or Barcelona), couchsurfing communities are almost entirely made up of "coffee or drink" profiles, which implies that people are not willing to host others, but are just there for some other reasons.

5. There are only three Schengen state consulates in Siberia-a German one in Novosibirsk, a Polish one and a Lithuanian one in Irkutsk. If one intends to visit another Schengen country, one should apply for a visa in that country's embassy or consulate, which means that individual applicants have to go from Siberia to Moscow.

6. http://www.couchsurfing.org/statistics.html?country_name=Russia (accessed 19 March 2012).

7. Fifteen interviews were conducted with couchsurfers from Krasnoiarsk and Irkutsk. As an additional source of data, I refer to the travelogue by Fleur Britten, a British journalist who has used couchsurfing for traveling from Moscow to Vladivostok (Britten 2009).

8. However, the situation is changing very fast and in 2012 the visitors to the "Wi-Fi Café" in Irkutsk could borrow an iPad for free if they did not have their own laptop with them. 
9. There are 618 members in the Trans-Siberian Train Group; see http:// www.Couchsurfing.org/group.html?gid=867 (accessed 4 December 2012).

10. An Argentinian couchsurfer with whom I hiked in the Khamardaban Mountains in March 2011 told me why he had decided to stay in Krasnoiarsk. He admitted that it was difficult for him to find any photographs of Krasnoiarsk on the Web, thus he could not really assess if the city was worth a visit. But he had found some positive references about Krasnoiarsk in the TransSiberian Train group forum; therefore, he decided to stay there for several days.

11. According to observations of key informants in these cities, obtained during a couchsurfers' meeting in Moscow and St. Petersburg in JanuaryFebruary 2008.

12. The Russian word kupe is derived from the French coupé (compartment).

13. The Russian word platskart goes back to the German Platzkarte (reservation for a seat or berth).

14. This is the author's personal experience from fieldwork. It was helpful to introduce myself as a researcher working in Portugal, and some respondents asked me about my educational and professional path and sometimes wanted to learn about opportunities to work or study abroad.

15. Small apartments built during the Khruschev period.

16. Conlon employs the concept of syncopation in order "to grasp the dynamic co-existence and influence of the multiple beats that shape social space" (2010: 73).

\section{Acknowledgments}

This article is based on data partly collected during field research for the project "Conditions and Limitations of Lifestyle Plurality in Siberia," carried out by researchers and research associates of the Siberian Studies Centre, Max Planck Institute for Social Anthropology, between 2008 and 2012. I want to thank the team members for many fruitful discussions. My thanks go to Joachim Otto Habeck for his valuable comments, and two anonymous reviewers who have helped me to improve this article.

\section{References}

Aitamurto, Kaarina. 2007. "Conceptualizations of Fascism and Anti-Fascism on Rodnoverie Internet Forums." Pp. 195-224 in Voices and Values of Young People: Representations in Russian Media, ed. Marjatta Vanhalla-Aniszewski and Lea Siilin. Helsinki: Aleksanteri Institute.

Andreoni, James. 1990. "Impure Altruism and Donations to Public Goods: A Theory of Warm-Glow Giving." Economic Journal 100 (401): 464-477.

Baerenholdt, Jorgen Ole. 2011. Coping with Distances: Producing Nordic Atlantic Societies. Oxford: Berghahn Books. 
Barth, Volker, Frank Halbach, and Bernd Hirsch, eds. 2010. Xenotopien: Verortungen des Fremden im 19. Jahrhundert [Xenotopias: Localizations of the strange in the nineteenth century]. Berlin: Lit Verlag.

Bialski, Paula. 2007. "Intimate Tourism: Friendships in a State of Mobility: The Case of the Online Hospitality Network." MA thesis, Institute of Sociology, University of Warsaw. http://intimatetourism.files.wordpress.com/ 2007/07/paulabialski-thesisma-intimatetourism.pdf (accessed 24 May 2011).

Bialski, Paula. 2011. "Technologies of Hospitality: How Planned Encounters Develop between Strangers." Hospitality $\mathcal{E}$ Society 1 (3): 245-260.

Britten, Fleur. 2009. "On the Couch. Tales of Couchsurfing a continent." London: Collins.

Buchberger, Sonja. 2011. "Hospitality, Secrecy and Gossip in Morocco: Hosting Couchsurfers Against Great Odds." Hospitality E Society 1 (3): 299-315.

Chen, De-Jung. 2011. "Global Concept, Local Practice: Taiwanese Experience of Couchsurfing." Hospitality $\mathcal{E}$ Society 1 (3): 279-297.

Conlon, Deirdre. 2010. "Fascinatin' Rhythm(s): Polyrhythmia and the Syncopated Echoes of the Everyday." Pp. 71-82 in Geographies of Rhythm: Nature, Place, Mobilities and Bodies, ed. T. Edensor. Farnham, UK: Ashgate.

Cooper, Julian. 2006. "The Internet as an Agent of Socio-Economic Modernisation of the Russian Federation." Pp. 285-304 in Modernisation in Russia since 1900, ed. M. Kangaspuro and J. Smith. Helsinki: Finnish Literature Society.

Delacruz, Peter, and Mike Claveria. 2011. "Trust and Social Capital on CouchSurfing and OkCupid." www.bjpeterdelacruz.com/files/ics691finalpaper .pdf (accessed 12 July 2012).

Gavriliuk, Vera. 2010. "Gopniki kak fenomen v srede molodezhi" [Gopniki as a phenomenon among youth]. Sotsis 1: 126-131.

Germann Molz, Jennie. 2007. “Cosmopolitans on the Couch: Mobile Hospitality and the Internet." Pp. 65-80 in Mobilizing Hospitality: The Ethics of Social Relations in a Mobile World, ed. J. Germann Molz and S. Gibson. Aldershot, UK: Ashgate.

Germann Molz, Jennie. 2012a. "Solidarity on the Move: Technology, Mobility and Activism in a Hospitality Exchange Network." Pp. 119-137 in Mobility and Communication Technologies in the Americas, ed. by P. Vannini, P. Jiron, O. B. Jensen, L. Budd, and C. Fisker. New York: Peter Lang.

Germann Molz, Jennie. 2012b. Travel Connections: Tourism, Technology and Togetherness in a Mobile World. London: Routledge.

Golovin, Valentin, and Mikhail Lur'e. 2008. “Ideologicheskie i territorial'nye soobshchestva molodezhi: megapolis, provintsial'nyi gorod, selo" [Ideological and territorial communities of youth: megapolis, provincial town, and village]. Etnograficheskoe obozrenie 1: 56-70.

Gullestad, Marianne. 2001. “Imagined Sameness: Shifting Notions of 'Us' and 'Them' in Norway." Pp. 32-57 in Forestillinger om "den Andre"/Images of 
Otherness, ed. L. A. Ytrehus. Kristiansand: HøyskoleForlaget/Norwegian Academic Press.

Gustafson, Per. 2009. “More Cosmopolitan, No Less Local: The Orientations of International Travelers." European Societies 11 (1): 25-47.

Habeck, Joachim Otto. 2008. “Conditions and Limitations of Lifestyle Plurality in Siberia: A Research Programme." Max Planck Institute for Social Anthropology Working Papers 104.

Hancock, Jeffrey T., and Catalina L. Toma. 2008. "Putting Your Best Face Forward: The Accuracy of Online Dating Photographs." Journal of Communication 59 (2): 367-386.

Jesudhass, James. 2011. Reciprocity beyond Borders: The Case of Couchsurfing Network in Hanoi, Vietnam. Dunedin: University of Otago Press.

Kustov, Alexander. 2012. “Internet i kul'turnaia globalizatsiia: Glokal'noe soobshchestvo kauchserferov Sankt-Peterburga" [Internet and cultural globalization: The glocal community of couchsurfers of St Petersburg]. Etnograficheskoe obozrenie 3: 105-117.

Pilkington, Hillary, Elena Omel'chenko, Moya Flynn, Ulyana Bliudina, and Elena Starkova. 2003. Looking West? Cultural Globalization and Russian Youth Cultures. University Park: Pennsylvania State University Press.

Pilkington, Hillary, Elena Omel'chenko, and Al'bina Garifzianova. 2010. Russia's Skinheads: Exploring and Rethinking Subcultural Lives. London: Routledge.

Popov, Vladimir. 2012. “The Culture of New Mobility in Russia: Networks and Flows Formation." Mobilities 7 (1): 151-169.

Pultar, Edward, and Martin Raubal. 2009a. "A Case for Space: Physical and Virtual Location Requirements in the Couchsurfing Social Network." Pp. 88-91 in Proceedings of the 2009 International Workshop on Location Based Social Networks (LBSN 2009), November 3, 2009, Seattle, Washington, USA. New York: Assoctiation for Computing Machinery. http://www.acm.org/ publications (accessed 4 December 2012).

Pultar, Edward, and Martin Raubal. 2009b. "Progressive Tourism: Integrating Social, Transportation, and Data Networks." Pp. 145-159 in Tourism Informatics: Visual Travel Recommender Systems, Social Communities, and User Interface Design, ed. N. Sharda. Hershey, PA: IGI Global.

Rizvi, Fazal. 2008. "Epistemic Virtues and Cosmopolitan Learning." Australian Educational Researcher 35 (1): 17-35.

Rosen, Devan, Pascal Roy Lafontaine, and Blake Hendrickson. 2011. "Couchsurfing: Belonging and Trust in a Globally Cooperative Online Social Network." New Media E Society 13 (6): 981-998.

Saito, Hiro. 2011. "An Actor-Network Theory of Cosmopolitanism." Sociological Theory 29 (2): 124-149.

Steylaerts, Vicky, and Sean O'Dubhghaill. 2011. “Couchsurfing and Authenticity: Notes Towards an Understanding of an Emerging Phenomenon. Hospitality $\mathcal{E}$ Society 1 (3): 261-278. 
Walker, Charles. 2010. "Space, Kinship Networks and Youth Transition in Provincial Russia: Negotiating Urban-Rural and Inter-Regional Migration." Europe-Asia Studies 62 (4): 647-669.

Waters, Malcolm. 2001. Globalization. London: Routledge.

Zuev, Dennis. 2008a. "The Practice of Free-Traveling: Young People Coping with Access in Post-Soviet Russia." Young 16 (1): 5-26.

Zuev, Dennis. 2008b. "Establishing Trust Offline: Visual-Oral Self-Presentations in the Global Hospitality Network." Paper presented at the International Sociological Association Forum of Sociology, 5-8 September, Barcelona.

Zuev, Dennis. 2011. "Couchsurfing as a Spatial Practice: Accessing and Producing Xenotopos." Hospitality and Society 1 (3): 227-244.

Zuev, Dennis. 2013. "Hosting Marco in Siberia: Couchsurfing Hospitality in an 'Out of the Way' Place." Pp. 65-82 in Couchsurfing cosmopolitanisms. Can tourism make a better world?, eds. D. Picard and S. Buchberger. Bielefeld. Transcript Verlag. 